\title{
AS ACÕES AFIRMATIVAS E OS DESAFIOS DA LUTA PELA IGUALDADE NA CONJUNTURA ATUAL
}

\author{
THE AFFIRMATIVE ACTIONS AND THE FIGHTING DEFIANCES FOR EQUALITY IN \\ THE CURRENT CONJUNCTURE
}
LAS ACCIÓNES AFIRMATIVAS Y LOS DESAFÍOS DE LA LUCHA POR LA IGUALDAD EN LA SITUACIÓN ACTUAL

Paulino de Jesus F. Cardoso* paulino.cardoso@gmail.com

\section{REVISTA PEDAGÓGICA \\ Revista do Programa de Pós-graduação em Educação da Unochapecó | ISSN 1984-1566 Universidade Comunitária da Região de Chapecó | Chapecó-SC, Brasil}

Como referenciar este artigo: CARDOSO, P. J. F. As ações afirmativas e os desafios da luta pela igualdade na conjuntura atual. Revista Pedagógica, Chapecó, v. 19, n. 40, p. 33-42, jan./abr. 2017. DOI: http://dx.doi.org/10.22196/rp.v19i40.3740

RESUMO: No presente texto, buscamos refletir acerca dos desafios da luta antirracista na conjuntura política atual, marcada especialmente pela demolição e corrupção das instituições democráticas e instalação de um Estado de Exceção, apoiado por parte expressiva das classes médias e altas deste país. Uns movidos pela aparente perda de prestígio social, outros pelo crescimento da participação política de populações vulneráveis que se converteu em acesso a bens e serviços jamais visto na história deste país. Entendemos que a Branquitude se tornou um obstáculo aos avanços democráticos das últimas décadas, em especial para as políticas de promoção de igualdade.

Palavras-chave: Brasil. Democracia. Igualdade Racial. Ações Afirmativas.

ABSTRACT: In the following paper, it is aimed to bethink the defiances of the antiracist struggle in the current political conjuncture, marked notably by the demolition and corruption of democratic institutions and the establishment of a State of Exception, supported by the middle and upper classes, where some are driven by the apparent loss of social prestige or the rising political participation of vulnerable populations, once it led to access of services never seen throughout these lands. It is believed that Whiteness has become an issue concerning democratic advances of the last decades to policies which promote equality.

Keywords: Brazil. Democracy. Racial Equality. Affirmative Actions.

RESUMEN: El presente texto, tiene elinteres de reflejar acerca de los desafíos de la lucha antirracista en la conjuntura política actual, fijada, especialmente por la demolición y corrupción de la sinstituciones democráticas e instalación de un Estado de excepción, apoyado por parte expresiva de las clases medias y altas del país. Unos movidos por la apariente perdida de prestigio social, otros por el crecimiento de la participación política de las pobaciones vulnerables que se volvieron un acceso a los bienes y servicios jamás visto en la história de Brasil. Asi, comprendemos que la Blanquitud es un obstáculo a los avances democráticos de las últimas décadas, en especial para las políticas de promoción de igualdad.

Palabras clave: Brasil. Democracia. Igualdad Racial. Acciones Afirmativas. 


\begin{abstract}
* Presidente da ABPN. Possui graduação em História pela Universidade Federal de Santa Catarina (1988), mestrado em História pela Pontifícia Universidade Católica de São Paulo (1993) e doutorado em História pela Pontifícia Universidade Católica de São Paulo (2004). Pró-Reitor de Extensão, Cultura e Comunidade da UDESC (2008/2012), membro da Comissão Assessora de Diversidade para Assuntos Relacionados a Educação dos Afro-Brasileiros - CADARA/ MEC (2003/2015), membro do Conselho Nacional de Promoção da Igualdade Racial - CNPIR/SEPPIR (2012/2015), Atualmente é consultor - Casa das Áfricas, membro de Comissão Acompanhamento da Lei de Cotas do Ministério da Educação e professor associado - dedicação integral da Universidade do Estado de Santa Catarina. É presidente da Associação Brasileira de Pesquisadores Negros. Tem experiência na área de História, com ênfase em História e Populações de Origem Africana no Brasil e Em Santa Catarina, atuando principalmente nos seguintes temas: negros, história, educação, Santa Catarina e populações de origem africana.
\end{abstract}

\section{INTRODUÇÃO}

Primeiramente e sempre: Fora Temer! Nós, brasileiros e brasileiras, temos a obrigação moral de denunciar o Golpe de Estado que se processa no Brasil.

Em segundo lugar, mas não menos importante, gostaria de agradecer a comissão organizadora do I SeminarioLatino-americano de EducaciónSuperior em Perspectiva Comparada-Descolonialidaddel saber y de losprocesos educativos enlos contextos de América Latina y el Caribe y de África Austral, nas pessoas do Professores Enrique Martinez Larrechea e Claudia Battestin pelo convite para esta importante rede de pesquisadores do sul do mundo.

Em terceiro lugar, creio ser fundamental explicitarmos o lugar de onde falamos: a Associação Brasileira de Pesquisadores Negros (ABPN), que, em parceria com o Consórcio Nacional de Núcleos de Estudos Afro-Brasileiros (NEABS), fundou mais de 150 NEABs, espalhados por todas as unidades da federação, o que nos torna, uma das mais importantes organizações antirracistas do país, credenciada para dialogar com grandes e tradicionais Organizações Não Governamentais, entidades nacionais do Movimento Negro como Movimento Negro Unificado, UNEGRO, APNS, Coordenação Nacional de Entidades Negras (CONEN), Rede Afro LGBT, Federação Nacional Associações de Pessoas com Doença Falciforme (FENAFAL). Ademais, recentemente, em um esforço de internacionalização, estamos integrando a Rede Integra - Racismo, Xenofobia e Identidas, UNAM, GT Universidades Interculturais da CLACSO, REDE IESAL - Ações Afirmativas para Afrodescendentes e Indígenas nas Instituições de Ensino Superior da América Latina e Caribe e WERA - Associação Mundial de Pesquisa em Educação.

Neste momento, buscamos refletir acerca dos desafios da luta antirracista na conjuntura política atual, marcada, especialmente pela demolição e corrupção das instituições democráticas e instalação de um Estado de Exceção, apoiado por parte expressiva das classes médias e altas desse país. Uns movidos pela aparente perda de prestígio social, outros pelo crescimento da participação política de populações vulneráveis que se converteu em acesso a bens e serviços jamais visto na história brasileira.

Nessas tensas disputas, emerge o poder avassalador dos Meios de Comunicação monopolistas. Apenas cinco famílias controlam rádio, canais de televisão, jornais e revistas impressos e on-line, portais de internet, tornadas instrumentos de ação política na defesa de seus interesses. Aliado a isso, temos o mais conservador Congresso Nacional da nossa jovem democracia, dominado por parlamentares milionários, comprometidos com lobbies de todo tipo e conhecidos pela associação à Bancada BBB: do Boi, da Bala e da Bíblia que pretendem nos devolver para a Idade Média europeia. Neste passo, corremos o risco de acordarmos com a revogação da Lei Áurea. 
A agenda conservadora atual que combina distribuição de privilégios, enquanto o trabalhador compromete $53 \%$ da sua renda com pagamentos de impostos, os brasileiros que recebem acima de $\underline{\mathrm{RS} \$ 4}$ milhões por ano, possuem apenas $35 \%$ tributável. O que faz do Brasil o paraíso dos super-ricos segunda a insuspeita ONU. Nosso país concede auxílio-moradia para juízes e membros do Ministério Público, mesmo morando na cidade onde trabalham. E acabou de conceder, em um ano de profunda retração econômica, um reajuste salarial de até $78 \%$ para os servidores do Judiciário, negociado pelo presidente do Supremo Tribunal Federal (STF), diretamente com Eduardo Cunha, então, presidente da Câmara dos Deputados, réu no próprio STF, agora cassado e preso preventivamente nas masmorras de Curitiba.

$\mathrm{E}$, igualmente, um ataque aos direitos duramente conquistados em décadas de lutas pelos trabalhadores e trabalhadoras brasileiras, como o fim na prática da Consolidação das Leis do Trabalho, a ser substituída pelas convenções coletivas, perfeitas para este ambiente de crescente desemprego, o projeto de terceirização total das atividades produtivas. Além de ataques a direitos sociais importantes como, Projeto de Emenda Constitucional (PEC) 215 que restringe a demarcação de terras indígenas e titulação de terras quilombolas, a revogação do Estatuto do Desarmamento, a criação do Estatuto da Família e a restrição ao uso de anticonceptivos, especialmente para vítimas de estupro e, mais recentemente, a descaracterização do Estatuto da Igualdade Racial, o fim do Programa Ciência Sem Fronteiras, do PROUNI, redução do FIES, PRONATEC e Programa Nacional de Enfrentamento do Analfabetismo e, agora, essa monstruosidade fascista, esta abominação autoritária chamada Escola Sem Partido.

Em verdade, os governantes, principalmente com a PEC 241, hoje PEC55, atacam a ideia de Estado Social presente na Constituição Federal de 1988. Um Estado onde liberdade e igualdade não se perdem na letra fria da lei, mas se configura como um projeto no qual brasileiros e brasileiras, feito comunidade política, são convidados a se engajar.

Hoje sabemos que os esforços institucionais da [no momento afastada] Presidente da República Dilma Rousseff para superar a crise política e governar, os quais-por terem sidoarticulados desde sua reeleição, em 2014, em um cenário econômico e geopolítico internacional nada favorável -, não deram certo por muito fatores. Entre eles, os próprios valores democráticos de Dilma Roussef. Essa governante esteve sempre comprometida com um projeto nacional de desenvolvimento com inclusão social; mas, por não haver vislumbrado a amplitude da conspiração que se avizinhava nem o peso dos atores externos, no qual os atentados (como o ocorrido na França em 2015) são apenas uma parte de uma história que envolve os esforços ocidentais, capitaneados pelos EUA visando à dominação de espectro global, em um mundo multipolar. 
Assim cabe abrir parênteses: vivemos à sombra da terceira Guerra Mundial, que se opera em diferentes teatros, sul da China, Leste da Europa, Turquia, Irã, Síria, Iêmen, tendo como foco o controle da Eurásia, onde estão 60\% da riqueza mundial. Daí a importância de organismos multipolares, da Organização Mundial de Comércio, do Mercosul, da CELAC e fundamentalmente do BRICS. Nestes vastos campos de lutas, a Síria emerge como a nossa nova Saraievo; nela, jogam o jogo dos tronos, semeando morte e sofrimento em toda parte. Praticamente expulsos da Turquia, derrotados na Ukrania e atolados no Iraque e Afeganistão, e, ainda, com a Europa enfraquecida e em dissolução, resta aos estadunidenses o seu velho quintal, conhecido pelo bordão "a América para os americanos" e dá-lhe semear golpes de Estado (Honduras, Paraguai e Brasil) e suas bases militares, duas somente na área do aquífero guarani.

\section{OS NEGROS E A UNIVERSIDADE}

Como muitos da minha geração, faço parte daqueles que acreditaram e acreditam que responsabilidade, trabalho duro e disciplina nos dariam uma carreira e uma perspectiva de futuro. Nós somos aqueles que foram iniciados no Movimento Negro nos anos 1980, graduamo-nos e nos qualificamos nos anos 1990 e, a partir desta década passamos a ocupar os cargos de docência universitária.

Entretanto, aos assumirmos nossas funções, deparamo-nos com o racismo institucional presente em nossas unidades de ensino. Não tínhamos bolsistas, espaço físico, suporte para pesquisa sobre temas relativos à África e a suas diásporas no Ocidente. Em suma, nossas preocupações não tinham lugar na tradição acadêmica. Recentemente, o então Ministro Renato Janine Ribeiro chamou de ideologia nossos esforços para descolonizar o ensino de História, presente no documento Base Nacional Comum. Nós, professores somos ameaçados por um projeto de lei em discussão no Congresso Nacional, denominado Escola Sem Partido, que pretende eliminar temas polêmicos como desigualdades de gênero, racismo, entre outros No Pará, alguns cientistas sociais acreditam que se pode construir um bom profissional da área sem Etnologia Indígena e Estudos Africanos e Afro-Brasileiros. Destaco, também, que atéem minha universidade, a UDESC, o curso de Geografia (bacharelado e licenciatura)foi pensado sem fazer nenhuma referênciaà África, América Latina e Ásia.

A memória dos intelectuais brancos é curta. Eles se esquecem de que foram estes os temas que configuraram as ciências sociais, a História e a Geografia em nosso país. Pior: no exercício de sua Branquitude epistemicida, descumprem a legislação em vigor e ameaçam ser descredenciados pelo Ministério da Educação. Um grande sociólogo, Guerreiros Ramos, negro e senador da República, afirmava com razão que o racismo é uma patologia do branco brasileiro. 
Nós somos frutos de uma antiga estratégia de luta antirracista, a qual considera a educação como instrumento de mobilidade individual e coletiva, de enfrentamento das desigualdades e emancipação social. Em verdade, pesquisadores como Willian Robson Soares Lucindo, Petrônio Domingues (2005), entre outros, em suas pesquisas têm indicado, no Movimento Negro, a centralidade da educação nas estratégias de mobilização e emancipação social dos descendentes de africanos.

\section{UM NOVO CICLO DE LUTA}

Vivemos um novo ciclo da luta por igualdade em nosso país e, consequentemente, o fim da agenda democrática que se configurou no fim da Ditadura Militar, e que, de algum modo, serviu de referência para as lutas democráticas nos últimos 30 anos.

Ao contrário dos anos 1970, não esperamos o bolo da economia crescer para, depois,distribuí-lo. Nós mudamos esse paradigma. Nós, ao longo dos últimos anos, sobre a batuta da sociedade civil organizada, em diálogo com um novo quadro político-partidário, produzimos uma revolução democrática em nosso país.

Estávamos substituindo o antigo projeto neoliberal, fundamentado na redução do papel do Estado, na liberalização dos mercados, na precarização das condições de trabalho e desarticulação da sociedade civil; por uma nova proposta para o país consagrado na fórmula crescimento econômico, combinado com enfrentamento da pobreza e combate às desigualdades.

No nosso campo, elaboramos uma pauta multiculturalista que deixou nu os mecanismos que reproduzem a dominação branca em nosso país. Ações universalistas articuladas à definição de políticas de combate às desigualdades raciais, tiveram o mérito de colocar o racismo e seus efeitos na agenda política do país.

Do ponto de vista institucional, a legitimidade das políticas de ação afirmativas foi reconhecida pelo Executivo, Judiciário e Legislativo. O Brasil tornou-se signatário de diferentes convenções internacionais, entre elas a Declaração e o Plano de Ação da III Conferência Internacional Contra o Racismo, Xenofobia e Intolerâncias Correlatas, em Durban, África do Sul.

Nos sistemas de ensino, em especial, no Governo Federal, em tese, construímos um arcabouço jurídico e administrativo, jamais visto, o qual está focado no combate às desigualdades raciais na Educação. As Leis Federais $\mathrm{n}^{0}$ $10.639 / 2003, \mathrm{n}^{0} 11.645 / 2008$, regulamentadas pelas Diretrizes Nacionais para a Educação das Relações Etnicorraciais e Ensino de História e Cultura Afro-Brasileira, Africana e Indígena, estabeleceram as regras por meio das quais se pretende enfrentar o racismo e promover o respeito à diversidade cultural no cotidiano escolar. Oque falta? Sem dúvida, o aprimoramento dos mecanismos de fiscalização 
do cumprimento das normas. Nesse sentido, uma reorientação do papel do INEP é fundamental. Enquanto os colonos brancos continuarem ditando o ritmo das mudanças, a Educação brasileira não avançará em direção a igualdade.

Em relação à formação inicial, hoje sabemos somente isso não basta. Mais do que políticas de ação afirmativa para o acesso, precisamos levar em consideração a permanência e o sucesso de nossos egressos. E isso significa pensar não só as Instituições Federais Ensino Superior (IFES) mas igualmente as instituições públicas, privadas e comunitárias, o que implica promover uma mudança de paradigma.

O que está em questão é a necessidade de aprofundar as políticas, de modo a definir metas e cronogramas. Nós aprovamos cotas no serviço público federal, mas vemos nossas instituições de ensino superior burlarem, de forma assustadora, as condições para efetivação da presença negra na docência universitária.

Igualmente, precisamos enfrentar as dificuldades para ampliar as oportunidades de acesso aos estudos pós-graduados em nossas instituições. Esse fato é demonstrado na tabela e nos gráficos a seguir:

Tabela 1 - Número de discentes por nível acadêmico, 2013 - 2015.

\begin{tabular}{|l|r|r|r|}
\hline \multicolumn{1}{|c|}{ Ano A } & \multicolumn{2}{|c|}{2013} & \multicolumn{1}{c|}{2015} \\
\hline \multicolumn{1}{|c|}{ Nivel Acadêmico } & \multicolumn{1}{c|}{ Frequência } & Frequência & \multicolumn{1}{c|}{ Frequência } \\
\hline DOUTORADO & 107.005 & 114.051 & 120.494 \\
\cline { 1 - 1 } MESTRADO & 164.090 & 166.334 & 169.209 \\
\hline MESTRADO & 24.705 & 28.754 & 34.671 \\
PROFISSIONAL & 295.800 & 309.139 & 324.374 \\
\hline Total & & & \\
\hline
\end{tabular}

Fonte: Plataforma Sucupira (CAPES/MEC), elaboração dos autores, novembro 2015 .

Gráfico 1 - Número de discentes por Raça/Cor

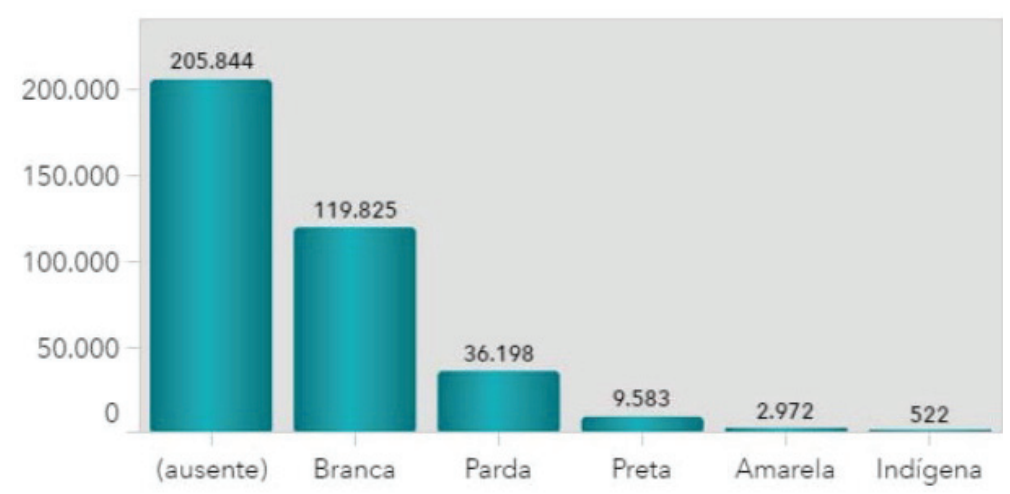

Fonte: Plataforma Sucupira (CAPES/MEC), elaboração dos autores, novembro 2015.

Para realizar a comparação do universo da PósGraduação com a população Brasileira retiram-se os discentes que não declararam a sua Raça/Cor para verificar o 
percentual do grupo de interesse na Pós-Graduação. Segue o gráfico com o percentual das infoemações declaradas.

Gráfico 2 - Percentual de discentes por Raça/Cor sem os discentes que não se declararam

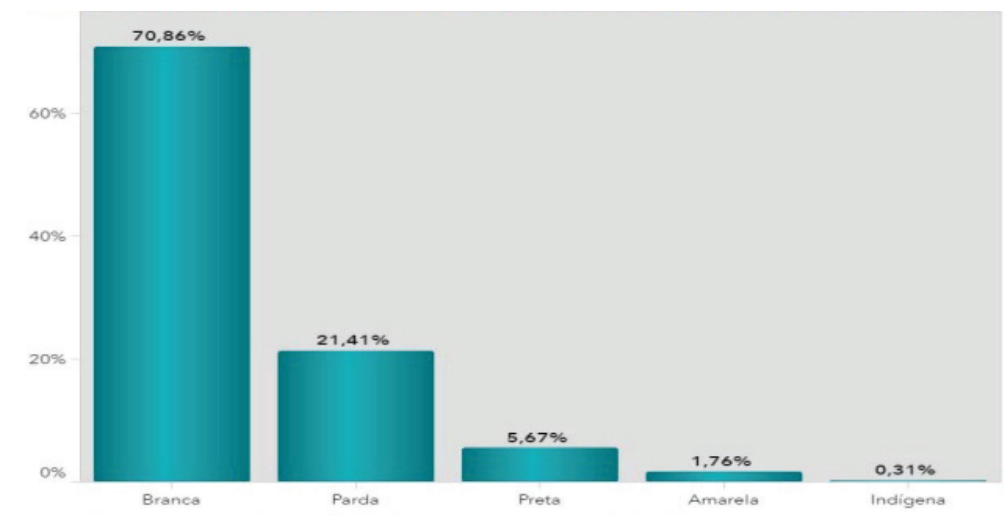

Fonte: Plataforma Sucupira (CAPES/MEC), elaboração dos autores, novembro 2015 .

E ampliar as oportunidades de acesso aos pós-graduados não será possível sem um diálogo, e este nem sempre será fraterno com a SESU/MEC, CAPES e CNPq, Devem ser criadas diretrizes que estimulem os programas de pós-graduação no país a, primeiramente, mas não apenas reservarem vagas para estudantes negros e negras. No final do Governo Dilma Roussef, às vésperas da votação da admissibilidade do processo de impeachment, nós fomos surpreendidos por uma decisão do Ministro da Educação, Aloisio Mercadante, de uma portaria que obriga as IFES a apresentar propostas de ações afirmativas na pós-graduação.

Foi uma iniciativa tímida, que não traduziu os resultados de seis meses de trabalho da Comissão de Inclusão Social da CAPES.Permitam-nos citar nosso relatório entregue à presidência da CAPES:

Após sucessivas reuniões, o GT constituído voltou a reunir-se em 8 de março de 2016, na sede da Capes em Brasília/DF, imbuído de suas responsabilidades, com reflexões inerentes à questão e, sobretudo, com base em informações contidas no relatório estatístico (Anexo A), extraído do Acervo Digital da CAPES, INEP e RAIS (MT), objetivando avançar no ideal de igualdade de oportunidades na educação, focando particularmente nos grupos mais vulneráveis, decidindo recomendar a adoção dos seguintes mecanismos de inclusão:

1. Sejam reservadas no prazo de três anos consecutivos, $10 \%, 20 \%$ e $30 \%$, respectivamente, das vagas dos programas de Mestrado, Mestrado Profissional e Doutorado, em instituições do Sistema Federal do Ensino Superior, para estudantes autodeclarados negros, indígenas, estudantes com deficiência, transtornos globais do desenvolvimento e altas habilidades. 
2. Todos os candidatos selecionados pelo critério anterior terão bolsas de estudo garantidas pela CAPES ou CNPq, durante o tempo já estabelecido para todo o sistema, na proporção determinada pelas duas instituições.

3. Candidatos com deficiência, indígenas e quilombolas, em razão de suas especificidades, poderão ter o valor das respectivas bolsas atribuídas até a quantidade máxima de 5 (cinco) bolsas ao mês, solicitadas à Capes e ao CNPq pelos programas de pós-graduação.

4. Todos os candidatos selecionados pelo critério 1 (um) serão prioritariamente atendidos pelas ações de apoio ao desenvolvimento das atividades da pós-graduação.

Em nosso entendimento, esses desencontros não podem ser interpretados apenas como desconhecimento de materiais pedagógicos ou experiências exitosas, mas como representação de um racismo institucional presente em todos os sistemas de ensino que tornam as escolas instrumentos de colonização mental e de reprodução de hierarquias sociais, os quais mantêm a população não branca brasileira na condição de trabalhadores dependentes desde o século XVI.

Como vem nos alertando Hannah Arendt (1998), o racismo e outras mazelas não são frutos da insanidade ou de monstruosidades de um ou outro sujeito, mas sim, inerentes à configuração da própria modernidade ocidental, ao exilarem metade da humanidade das suas condições de existência, jogarem a outra dentro de suas próprias cabeças e banirem a experiência como base para o conhecimento e a verdade.

Durante os últimos 30 anos, acreditamos no caminho proposto pelos canais democráticos, organizamos a sociedade civil, campanhas de esclarecimento, luta institucional em diferentes esferas, e participamos dos mais diferentes partidos políticos. Conseguimos, assim, enfrentar o mito da democracia racial brasileira.

Entretanto, para nosso desespero, nunca nos encarceraram tanto, nunca nos mataram tanto. Certamente, dados das agências de saúde devem indicar o brutal impacto do sofrimento psíquico associado ao racismo na degradação de nossa saúde mental. Por último, a atual avalanche conservadora e fascista, capitaneada pelo fundamentalismo cristão, ameaça destruir tudo o que construímos de liberdades nas últimas décadas.

Em minha opinião, nós chegamos ao limite daquilo que os descendentes de colonos europeus, autodenominados brancos, estão dispostos a negociar. Sejam eles de esquerda ou de direita, sejam conservadores ou progressistas, a realidade é que controlam os mecanismos de legitimação democrática e grande parte de nós, de nossas organizações do movimento social, as quais foram reduzidas a ONGs que vivem de migalhas do Estado ou da filantropia. 
O Golpe de Estado e a conduta errática do Governo Provisório têm indicado que precisamos voltar ao básico, ancorados nas lutas por libertação de povos oprimidos em todo mundo. Necessitamos focar nossa ação na educação política da nossa população para promover o enfrentamento do colonialismo; afinal, o racismo é somente isso: a face contemporânea do colonialismo. Aqueles que detêm os privilégios da distribuição de status, prestígio e poder não cometeram suicídio político por terem sido esclarecidos da natureza racista de suas ações.

Por outro lado, aqueles que ocupam espaços de poder e não se acham vinculados a nós, nos veem como um problema para os governos. E, em razão disso, não passam de novos administradores coloniais, novos feitores da eterna Casa Grande. O exercício da ação governamental não pode servir apenas as nossas redes de poder, as nossas afinidades eletivas. Deve ser instrumento de fortalecimento das organizações do campo antirracista.

Hoje, reconhecemos que muitas foram as conquistas a ser comemoradas, em especial, nas últimas décadas termos colocado o combate ao racismo na agenda política de nosso país. De um modo geral, nós somos a expressão mais legítima do povo brasileiro. Logo, o racismo é um obstáculo para a plena cidadania no Brasil.

\section{O PAPEL ESTRATÉGICO DOS NÚCLEOS DE ESTUDOS AFRO-BRASILEIROS}

Nós acreditávamos (e acreditamos) que os núcleos de estudos afro-brasileiros poderiam qualificar a luta antirracista. Entretanto, nós subestimamos a capacidade de cooptação dos sistemas educacionais, marcados por modelos eurocêntricos e coloniais, que tornam muitos de nós cativos de nossos currículos, nosso pertencimento e aceitação pelos coronéis da academia (bonzinhos ou não).

Para nós ciência sem compromisso, ciência sem inserção nas culturas populares nos torna a todos legítimos administradores coloniais, capatazes da Casa Grande. Portanto, um acadêmico decente é aquele que aceita o desafio de tornar-se orgânico da massa africana e afrodescendente, que contribui para formar quadros e dar suporte ao movimento social e para os gestores de promoção de igualdade racial.

No entanto, nossa tarefa mais importante é colaborar com a Educação Básica na desmontagem da máquina colonial. Em especial, o colonialismo mental que nos impede de pensar para além do estabelecido, para além do já dado.

Nós, companheiros e companheiras, usando uma imagem judaica, subimos a montanha e vimos a terra prometida. Nossa tarefa: parir a geração que, à frente do nosso povo, tornará esse país uma terra de homens e mulheres livres. 


\section{REFERÊNCIAS}

ANDREWS, George Reid. Negros e brancos em São Paulo: (1888-1988). Bauru: EDUSC, 1998.

APPIAH, Anthony. Na casa de meu pai:a África na filosofia da cultura. Rio de Janeiro: Contraponto, 1997.

ARENDT, Hannah. Origens do totalitarismo.São Paulo: Companhia das Letras, 1998.

AZEVEDO, Celia Maria Marinho de. Onda Negra, Medo Branco: O Negro no Imaginário das Elites, Brasil, século XIX. Rio de Janeiro: Paz e Terra, 1987.

CHALHOUB, Sidney. Cidade febril:cortiços e epidemias na corte imperial. São Paulo: Companhia das Letras, 1996.

DOMINGUES, Petrônio. Movimento da negritude: uma breve reconstrução histórica. Mediações - Revista de Ciências Sociais, Londrina, v. 10, n.1, p. 25-40, jan./jun. 2005.

HERNANDEZ, Leila M. G. A África na sala de aula:visita à história contemporânea. 3. ed. São Paulo: Selo Negro, 2008.

LUCINDO, Willian Robson Soares.

MATTOS, Hebe Maria. Das Cores do Silêncio. Os significados da liberdade no sudeste escravista - Brasil, Séc. XIX. 2. ed. Rio de Janeiro: Nova Fronteira, 1998.

RIOS, Ana Lugão; MATTOS, Hebe Maria. Memórias do Cativeiro: família, trabalho e cidadania no pós-abolição. Rio de Janeiro: Civilização Brasileira, 2005.

ROLNIK, Raquel. Cada um no seu lugar! São Paulo, início da industrialização: geografia do poder. 1981. Dissertação (Mestrado em Arquitetura e Urbanismo) Programa de Pós-Graduação emArquitetura e Urbanismo da Universidade de São Paulo (FAU/USP), São Paulo, 1981.

SCHWARCZ, Lilia Moritz. Retrato em branco e NegroJornais, escravos e cidadãos em São Paulo no final do século XIX. São Paulo: Companhia das Letras, 1987.

SCHWARCZ, Lilia Moritz. O Espetáculo das Raças: Cientistas, Instituições e Questão Racial no Brasil de 18701930. São Paulo: Cia. das Letras, 1993.

SERRANO, Carlos Moreira Henriques; WALDMAN, Maurício. Memória D'África: a temática africana em sala de aula. 2. ed. São Paulo: Cortez, 2008. 